\title{
Surveillance and Testing for Middle East Respiratory Syndrome Coronavirus, Saudi Arabia, March 2016-March 2019
}

\author{
Abdullah Alzahrani, Stephanie A. Kujawski, Glen R. Abedi, Safaa Tunkar, \\ Holly M. Biggs, Nada Alghawi, Hani Jokhdar, Abdullah M. Assiri, John T. Watson
}

During March 2016-March 2019, a total of 200,936 suspected cases of Middle East respiratory syndrome coronavirus infection were identified in Saudi Arabia; infections were confirmed in 698 cases $(0.3 \%$ [0.7/100,000 population per year]). Continued surveillance is necessary for early case detection and timely infection control response.

$\mathrm{M}$ iddle East respiratory syndrome coronavirus (MERS-CoV) can cause severe respiratory illness and has a reported case-fatality rate of $\approx 35 \%$ (1). Transmission typically occurs through close contact with MERS-CoV-infected patients, particularly in healthcare settings $(2,3)$, or through contact with dromedaries (4). Most cases worldwide have been reported by Saudi Arabia (1).

By using the Health Electronic Surveillance Network (HESN), a national electronic surveillance platform, the Saudi Arabia Ministry of Health $(\mathrm{MoH})$ monitors MERS-CoV testing and cases throughout the country. Since 2015, clinicians and health authorities have been mandated to report all suspected MERS-CoV cases to HESN. In April 2018, the MoH revised the case definition for suspected MERS-CoV (5). This change provided an opportunity to assess testing practices under 2 different case definitions. We describe trends in MERS-CoV surveillance and laboratory testing in Saudi Arabia during March 1, 2016-March 20, 2019.

\section{The Study}

In Saudi Arabia, persons meeting the $\mathrm{MoH}$ case definition for suspected MERS-CoV infection are tested

Author affiliations: Ministry of Health, Riyadh, Saudi Arabia (A. Alzahrani, S. Tunkar, N. Alghawi, H. Jokhdar, A.M. Assiri); Centers for Disease Control and Prevention, Atlanta, GA, USA (S.A. Kujawski, G.R. Abedi, H.M. Biggs, J.T. Watson)

DOI: https://doi.org/10.3201/eid2607.200437 for the virus (Table 1, https:/ / wwwnc.cdc.gov/EID/ article/267/20-0437-T1.htm) (5,6). Persons may also be tested if recommended by an infectious disease consultant or if they had exposure to a MERS-CoV patient $(5,6)$. In April 2018, the $\mathrm{MoH}$ published a 4-category revision to the 2015 case definition, with the goal of making the definition more specific (Table 1) $(5,6)$. This revision was implemented in HESN in July 2018.

Information on suspected and confirmed cases is submitted electronically to HESN. For each suspected MERS-CoV case, the treating hospital creates an electronic record in HESN and submits a clinical sample to a designated laboratory for confirmatory testing. After testing is complete, the laboratory updates the electronic record in HESN with the results. Upon report of a confirmed case, additional clinical and epidemiologic data are entered into the HESN system by the hospital, local health authorities, or both.

We analyzed demographic and laboratory data for suspected and confirmed MERS-CoV cases reported to HESN during March 1, 2016-March 20, 2019 by using Microsoft Excel (https:/ / www.microsoft.com) and SAS 9.4 (https://www.sas.com). For this analysis, we defined a suspected case as suspected MERS$\mathrm{CoV}$ infection in a person with compatible symptoms during the study period, with $>14$ days separating illness episodes for persons in whom MERS-CoV infection is suspected more than once. We defined a confirmed case as laboratory confirmation of MERS$\mathrm{CoV}$ infection in a person during the study period. By using $\mathrm{MoH}$ population estimates (7), we calculated rates of testing and positivity for the country, by local Health Affairs Directorate (HAD), and for Hajj pilgrims.

During the study period, 200,936 suspected MERS-CoV case-patients were tested and their cases 
Table 2. Demographic characteristics of persons with suspected and confirmed MERS-CoV infection, Health Electronic Surveillance Network, Saudi Arabia, March 1, 2016-March 20, 2019*

\begin{tabular}{|c|c|c|c|c|}
\hline Characteristic & Total & Confirmed & Not confirmed & \% Positive (confirmed) \\
\hline Overall & 200,936 & $698(0.3)$ & $200,238(99.7)$ & 0.3 \\
\hline Age, y, median (IQR) & $47(28-67)$ & $54(40-65)$ & $47(28-67)$ & \\
\hline \multicolumn{5}{|l|}{ Age group, y } \\
\hline $0-14$ & $17,455(8.7)$ & $3(0.4)$ & $17,452(8.8)$ & 0.02 \\
\hline $15-34$ & $54,483(27.3)$ & $121(18.0)$ & $54,362(27.3)$ & 0.2 \\
\hline $35-49$ & $33,993(17.0)$ & $164(24.3)$ & $33,829(17.0)$ & 0.5 \\
\hline $50-65$ & $41,283(20.7)$ & $228(33.8)$ & $41,055(20.6)$ & 0.6 \\
\hline$>65$ & $52,400(26.3)$ & $158(23.4)$ & $52,242(26.3)$ & 0.3 \\
\hline Total & 199,614 & 674 & 198,940 & \\
\hline Missing & $1,322(0.7)$ & $24(3.4)$ & $1,298(0.6)$ & \\
\hline \multicolumn{5}{|l|}{ Sex } \\
\hline M & $108,940(54.3)$ & 517 (74.1) & $108,423(54.2)$ & 0.5 \\
\hline $\mathrm{F}$ & $91,822(45.7)$ & 181 (25.9) & $91,641(45.8)$ & 0.2 \\
\hline Total & 200,762 & 698 & 200,064 & \\
\hline Missing & $174(0.09)$ & 0 & $174(0.09)$ & \\
\hline \multicolumn{5}{|l|}{ Nationality } \\
\hline Saudi & $146,254(72.8)$ & $501(71.8)$ & $145,753(72.8)$ & 0.3 \\
\hline Non-Saudi & $54,682(27.2)$ & $197(28.2)$ & $54,485(27.2)$ & 0.4 \\
\hline Total & 200,936 & 698 & 200,238 & \\
\hline Missing & 0 & 0 & 0 & \\
\hline \multicolumn{5}{|l|}{ Healthcare personnel } \\
\hline Yes & $9,289(5.6)$ & $67(11.2)$ & $9,222(5.6)$ & 0.7 \\
\hline No & $155,825(94.4)$ & $531(88.8)$ & $155,294(94.4)$ & 0.3 \\
\hline Total & 165,114 & 598 & 164,516 & \\
\hline Missing & $35,822(17.8)$ & $100(14.3)$ & $35,722(17.8)$ & \\
\hline
\end{tabular}

${ }^{*}$ Values are no. (\%) unless indicated. IQR, interquartile range; MERS-CoV, Middle East respiratory syndrome coronavirus.

reported to HESN; MERS-CoV was confirmed in 698 case-patients $(0.3 \%)$ (Table 2$)$. Overall, $54.3 \%$ of suspected case-patients were male, $72.8 \%$ were Saudi nationals, and the median age was 47 years (interquartile range 28-67 years). Among suspected case-patients for whom healthcare personnel status was available, 5.6\% (n=9,222) were healthcare personnel. Among confirmed case-patients, 517 (74.1\%) were male, 501 (71.8\%) were Saudi nationals, and the median age was 54 years (interquartile range 40-65 years). The age group with the highest proportion of confirmed case-patients was 50-65 years $(0.6 \%)$, and the group with the lowest proportion was $0-14$ years $(0.02 \%)$. Healthcare personnel status was reported for $598(85.7 \%)$ confirmed case-patients; among these, $11.2 \%(n=67)$ were healthcare personnel. Outcome information was available for $84.0 \%(n=586)$ of the confirmed case-patients, 164 (28.0\%) of whom died.

Each surveillance year, an average of 66,979 (range $60,659-77,886)$ suspected case-patients were tested for MERS-CoV. On average, 5,431 (range 2,836-9,154) suspected case-patients were tested monthly during the study period (Figure). The average monthly number of suspected case-patients tested did not change

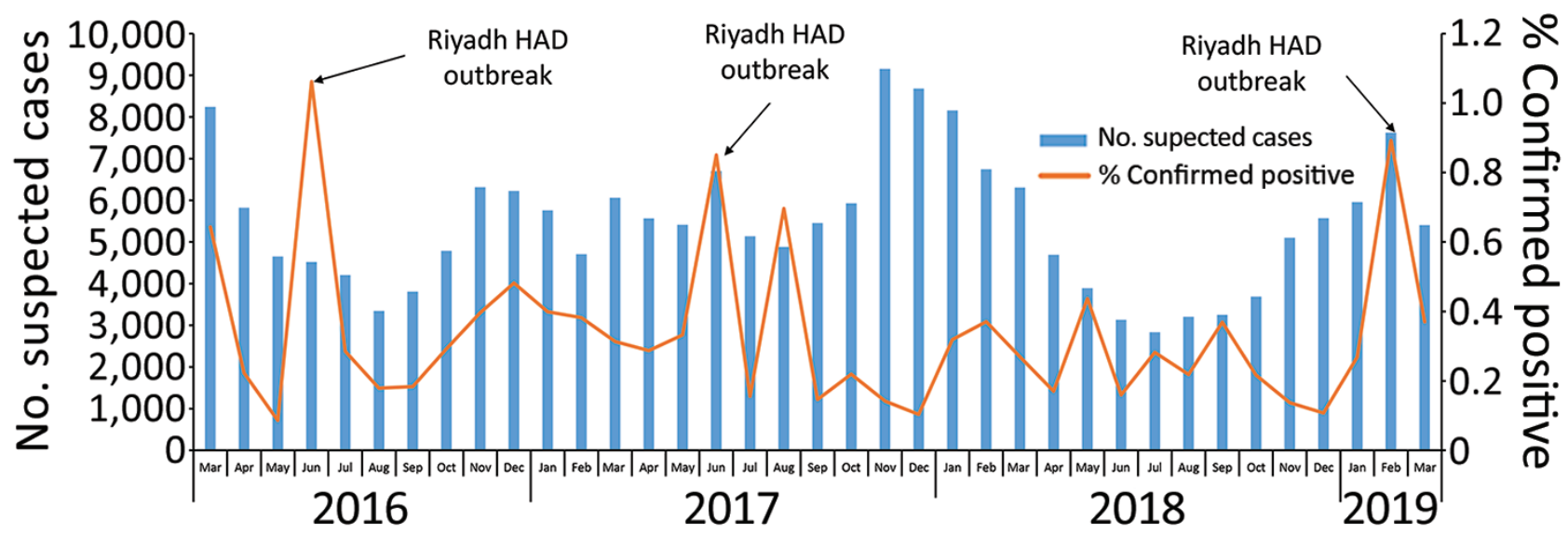

Figure. Number of suspected cases and percentage of confirmed positive cases of Middle East respiratory syndrome, Health Electronic Surveillance Network, Saudi Arabia, March 1, 2016-March 20, 2019. HAD, Health Affairs Directorate. 
significantly from before (5,654 tests during March 2016-June 2018) to after (4,914 tests during August 2018-February 2019) the case definition change $(p=$ 0.31). Overall, and both before and after the definition change, the average monthly percentage of suspected case-patients testing positive was $0.3 \%$. Peaks in positivity occurred in June 2016 (1.1\%), June 2017 (0.9\%), and February 2019 (0.9\%).

Annually, 203.0 suspected case-patients/100,000 population were tested for MERS-CoV, and 0.7/ 100,000 population were positive (Table 3 ). Testing and positivity rates did not vary substantially from year to year (Appendix Table 1, https:/ / wwwnc.cdc. gov/EID/article/26/7/20-0437-App1.xlsx). Riyadh HAD had the highest annual testing rate (328.0 suspected cases $/ 100,000$ per year). The highest positivity rate per population was in Jouf HAD (2.5 confirmed cases/100,000 population per year) and was largely attributable to an August 2017 outbreak. The study period encompassed 3 Hajj pilgrimage seasons; during these periods, 2,738 pilgrims were tested for MERS-CoV, none of whom tested positive.

For $82.2 \%$ of persons with suspected MERS-CoV infection, a reason for testing was reported (Appendix Table 2). Most were tested because they had signs of pneumonia or acute respiratory distress syndrome $(69.9 \%)$. Testing because of an epidemiologic link accounted for the highest proportion of positive results overall $(0.8 \%)$. A higher proportion were tested because of an epidemiologic link after the definition change $(19.5 \%)$ than before $(7.5 \%)$.

\section{Conclusions}

Saudi Arabia continues to perform extensive surveillance and testing for MERS-CoV. During the 3-year study period, the $\mathrm{MoH}$ tested $>65,000$ suspected MERS-CoV case-patients per year on average. Of these, $0.3 \%$ were positive for MERS-CoV, representing 0.7 confirmed cases $/ 100,000$ population per year. As a robust, national surveillance system, HESN enables the geographic and temporal monitoring of trends in testing and surveillance. Compared with HESN MERS-CoV surveillance data from 2015-2016, the percentage of suspected case-patients testing positive $(0.7 \%)$ and the rate of confirmed cases $(1.2 / 100,000$ population) decreased (8). Peaks in percentage positivity corresponded to documented MERS-CoV outbreaks (9-11). The few large recent outbreaks and the reduction in cases might be indicative of robust testing and contact-tracing efforts and early intervention for healthcare infection control.

During the study period, the case definition for suspected cases was revised with the goal of maintaining the sensitivity of the case definition while increasing specificity. Based on limited data $(7 \mathrm{com}-$ plete months of data postrevision), the average number of monthly tests remained constant before and after this change. The change in the case definition

\begin{tabular}{|c|c|c|c|c|c|}
\hline $\begin{array}{l}\text { Local Health Affairs } \\
\text { Directorate }\end{array}$ & Population* & $\begin{array}{c}\text { No. confirmed } \\
\text { cases/no. } \\
\text { suspected cases }\end{array}$ & $\begin{array}{l}\% \text { Confirmed } \\
\text { positive }\end{array}$ & $\begin{array}{c}\text { No. suspected } \\
\text { cases } / 100,000 \\
\text { population per year }\end{array}$ & $\begin{array}{c}\text { No. confirmed } \\
\text { cases/100,000 } \\
\text { population per year }\end{array}$ \\
\hline Riyadh & $8,216,284$ & $340 / 80,852$ & 0.4 & 328.0 & 1.4 \\
\hline Jeddah & $4,626,109$ & $37 / 18,929$ & 0.2 & 136.4 & 0.3 \\
\hline Eastern & $3,228,261$ & $16 / 15,856$ & 0.1 & 163.7 & 0.2 \\
\hline Makkah & $2,319,426$ & $8 / 13,843$ & 0.06 & 198.9 & 0.1 \\
\hline Madinah & $2,132,679$ & $25 / 13,334$ & 0.2 & 208.4 & 0.4 \\
\hline Aseer & $1,822,189$ & $24 / 5,560$ & 0.4 & 101.7 & 0.4 \\
\hline Jazan & $1,567,547$ & $0 / 1,082$ & 0.0 & 23.0 & 0.0 \\
\hline Qaseem & $1,423,935$ & $85 / 9,873$ & 0.9 & 231.1 & 2.0 \\
\hline Taif & $1,301,778$ & 25/6,342 & 0.4 & 162.4 & 0.6 \\
\hline Ahsa & $1,224,600$ & $32 / 13,009$ & 0.2 & 354.1 & 0.9 \\
\hline Tabouk & 910,030 & $9 / 2,848$ & 0.3 & 104.3 & 0.3 \\
\hline Hail & 699,774 & $11 / 4,946$ & 0.2 & 235.6 & 0.5 \\
\hline Najran & 582,243 & $32 / 2,951$ & 1.1 & 168.9 & 1.8 \\
\hline Bahah & 476,172 & $4 / 2,163$ & 0.2 & 151.4 & 0.3 \\
\hline Hafr Al-Baten & 447,464 & $8 / 681$ & 1.2 & 50.7 & 0.6 \\
\hline Bishah & 389,686 & $5 / 1,131$ & 0.4 & 112.1 & 0.4 \\
\hline Nothern & 365,231 & $8 / 855$ & 0.9 & 78.0 & 0.7 \\
\hline Jouf & 339,198 & $25 / 2,885$ & 0.9 & 283.5 & 2.5 \\
\hline Qunfudah & 310,453 & $1 / 412$ & 0.2 & 44.2 & 0.1 \\
\hline Quarayyat & 169,277 & $3 / 466$ & 0.6 & 91.8 & 0.6 \\
\hline Total & $32,552,336$ & $698 / 198,198$ & 0.4 & 203.0 & 0.7 \\
\hline Hajj pilgrims & $2,352,122$ & $0 / 2,738$ & 0.0 & 38.8 & 0.0 \\
\hline
\end{tabular}


is reflected in the reasons for testing persons with suspected MERS-CoV infection. A comparison of the reasons for testing before and after the change found that most persons were tested because they had signs of pneumonia or acute respiratory distress syndrome. Unsurprisingly, in both periods, the highest percentage positive was among those with an epidemiologic link to a MERS-CoV patient or exposure to dromedaries.

Comparing data from before and after the case definition change, however, was limited by the relatively short period examined after the definition change and a high percentage of missing data, particularly during implementation of the revised case definition. Although the case definition change took effect in April 2018, HESN was not updated to reflect the change until July 2018. This lag might have affected reporting, and actual implementation of the case definition change likely varied by site. In addition, completeness of the data varied and was likely influenced by differential reporting practices, which affected the availability of data for analysis. Targeted efforts continue to improve the accuracy and completeness of reporting. Additional analysis using more complete data over a longer period would be informative to determine whether the revised case definition might result in changes in testing practices.

Surveillance for MERS-CoV in Saudi Arabia captures and provides important information on suspected and confirmed cases and trends in testing. Continued robust MERS-CoV surveillance is pivotal for the early ascertainment of cases and the effective implementation of control measures.

\section{About the Author}

Dr. Abdullah Alzahrani is the general supervisor of the Health Electronic Surveillance Network, Ministry of Health, Saudi Arabia. His primary research interests include public health surveillance for infectious diseases.

\section{References}

1. World Health Organization. MERS situation update 2019 Sep [cited 2019 Oct 18]. http:/ / applications.emro.who.int/docs/ EMROPub-MERS-SEP-2019-EN.pdf
2. Assiri A, McGeer A, Perl TM, Price CS, Al Rabeeah AA, Cummings DA, et al.; KSA MERS-CoV Investigation Team. Hospital outbreak of Middle East respiratory syndrome coronavirus. N Engl J Med. 2013;369:407-16. https:// doi.org/10.1056/NEJMoa1306742

3. Oboho IK, Tomczyk SM, Al-Asmari AM, Banjar AA, Al-Mugti H, Aloraini MS, et al. 2014 MERS-CoV outbreak in Jeddah - a link to health care facilities. N Engl J Med. 2015;372:846-54. https:// doi.org/10.1056/NEJMoa1408636

4. Hui DS, Azhar EI, Kim YJ, Memish ZA, Oh MD, Zumla A. Middle East respiratory syndrome coronavirus: risk factors and determinants of primary, household, and nosocomial transmission. Lancet Infect Dis. 2018;18:e217-27. https://doi.org/10.1016/S1473-3099(18)30127-0

5. Ministry of Health of the Kingdom of Saudi Arabia. Middle East respiratory syndrome coronavirus: guidelines for healthcare professionals 2018 [cited 2019 Oct 18]. https:/ / www.moh.gov.sa/ccc/healthp/regulations/ documents/ mers-cov\%20guidelines\%20for\%20healthcare \%20professionals \%20-\%20may\%202018\%20-\%20v5.1\%20 $\% 281 \% 29$.pdf

6. Ministry of Health of the Kingdom of Saudi Arabia. Infection prevention and control guidelines for Middle East respiratory syndrome coronavirus (MERS-CoV) infection 2015. 3rd edition [cited 2019 Oct 18]. https:/ / www.moh.gov. sa/Documents/2015\%20update.pdf

7. Ministry of Health of the Kingdom of Saudi Arabia. Annual statistical book 2017 [cited 2019 Oct 18]. https:/ / www.moh. gov.sa/en/ministry/statistics/book/documents/ annual-statistical-book-1438h.pdf

8. Saeed AA, Abedi GR, Alzahrani AG, Salameh I, Abdirizak F, Alhakeem R, et al. Surveillance and testing for Middle East respiratory syndrome coronavirus, Saudi Arabia, April 2015-February 2016. Emerg Infect Dis. 2017;23:682-5. https://doi.org/10.3201/eid2304.161793

9. Alanazi KH, Killerby ME, Biggs HM, Abedi GR, Jokhdar H, Alsharef AA, et al. Scope and extent of healthcare-associated Middle East respiratory syndrome coronavirus transmission during two contemporaneous outbreaks in Riyadh, Saudi Arabia, 2017. Infect Control Hosp Epidemiol. 2019;40:79-88. https://doi.org/10.1017/ice.2018.290

10. World Health Organization. Middle East respiratory syndrome coronavirus (MERS-CoV) - Saudi Arabia: disease outbreak news, 21 Jun 2016 [cited 2019 Oct 18]. https:/ / www.who.int/csr/don/21-june-2016-merssaudi-arabia

11. World Health Organization. Middle East respiratory syndrome coronavirus (MERS-CoV) - the Kingdom of Saudi Arabia: disease outbreak news update, 24 April 2019 [cited 2019 Oct 18]. https://www.who.int/csr/don/24-April2019-mers-saudi-arabia

Address for correspondence: Glen R. Abedi, Centers for Disease Control and Prevention, 1600 Clifton Rd NE, Mailstop H24-5, Atlanta, GA 30329-4027, USA; email: huv3@cdc.gov 